\title{
5. Public-private partnerships for wider and equitable access to climate technologies
}

\section{Elisa Morgera and Kati Kulovesi*}

Technology plays an important role in the battle against climate change. To prevent dangerous climate change the world must shift to low-carbon and high-efficiency technologies in key sectors, such as power generation, transport and energy use. ${ }^{1}$ This fundamental transformation, also characterized as 'energy revolution', ${ }^{2}$ constitutes a considerable challenge. According to the encouraging message by the Intergovernmental Panel on Climate Change (IPCC), the necessary technologies are either already available (but are currently more expensive than fossil fuel-based options) or are expected to be commercialized in the coming decades. ${ }^{3}$ However, the IPCC also found that appropriate incentives must be in place for the development, acquisition, deployment and diffusion of low-emissions technologies and for addressing barriers. ${ }^{4}$

Effecting the 'energy revolution' requires strengthening international cooperation around climate technologies, both between developed and developing countries, and increasingly also between developing countries. ${ }^{5}$ The challenge is an urgent one. Around 1.5 billion people are currently estimated to lack access to energy. ${ }^{6}$ Fuelled by population growth and economic development, the world's energy needs are increasing rapidly. To meet such needs the world is projected to invest tens of trillions of dollars into energy infrastructure and power generation by 2030 , with approximately half of this in developing countries. ${ }^{7}$ This infrastructure will be used for 30 years or more, meaning that the sustainability of these investments and technologies will be crucial in determining whether the world will be able to avoid catastrophic climate change.

A majority of these investments will be made by the private sector, which is also expected to play a key role in development and deployment of climate-friendly technologies. Engaging the private sector in efforts to 
mitigate climate change is therefore fundamentally important and requires the establishment of appropriate policy frameworks and incentives. A well-functioning carbon market, carbon taxes and other measures setting a price for greenhouse gas emissions are widely viewed as essential in this respect. ${ }^{8}$ This is because setting an adequate price for carbon should direct investment towards climate-friendly technologies and create incentives for the private sector to develop and deploy them. In addition, other measures are likely to be needed to promote private sector engagement in the development and deployment of climate technologies, such as fiscal incentives, capital grants, feed-in tariffs, subsidies, and so on. ${ }^{9}$ The public and private sectors will also need to cooperate regarding research and development (R\&D). ${ }^{10}$ Based on past experiences in the international climate policy context, other kinds of public-private partnerships also seem necessary. It has been argued that technology transfer has not occurred 'under artificial conditions of subsidies and grants' but requires long-term and reliable cost recovery. ${ }^{11}$ Furthermore, technology transfer should take into account the needs and concerns of local communities and stakeholders. ${ }^{12}$ This is due to the fact that '(m)any historic attempts at technology transfer have failed because intended users have not understood or even opposed new technologies, or because planners have failed to appreciate the impacts of technological change on the prices and availabilities of local resources'.$^{13}$ Enhanced cooperation between companies that deploy environmental technologies and local communities therefore appears necessary. ${ }^{14}$

The UN Framework Convention on Climate Change (UNFCCC) and its Kyoto Protocol are central in the international legal framework governing climate technologies and both include commitments concerning technology cooperation. It is, however, commonly accepted that international cooperation on climate technologies must be strengthened to effectively respond to the climate change challenge. Accordingly, technology has been identified as one of the key building blocks in the ongoing negotiations for a future climate regime under the UNFCCC. ${ }^{15}$ As a result of the negotiations, the 2010 UN Climate Change Conference in Cancun resulted in basic agreement on a new Technology Mechanism which consists of the Technology Executive Committee and the Climate Technology Center and Network. Further progress was subsequently made at the 2011 UN Climate Change Conference in Durban, where agreement was reached to make the Technology Mechanism fully operational in 2012; as this chapter was written before the Durban Conference, it will focus on developments which took place before then. 
Interestingly for the present focus, the mandate of the new Technology Mechanism includes facilitating international public-private partnerships. ${ }^{16}$ Against this background, this chapter focuses on opportunities to use public-private partnerships to accelerate technology transfer under the UNFCCC. It first provides an overview of technology cooperation under the UNFCCC to date and then proceeds to examine experiences in technology transfer under the Clean Development Mechanism (CDM), which succeeded in closely engaging the private sector in its implementation. This chapter then focuses on the new Technology Mechanism as the future institutional framework for technology cooperation under the UNFCCC. With a view to drawing useful lessons for the new Mechanism it will then turn to public-private partnership initiatives under other multilateral environmental agreements (MEAs). The most prominent example is the Basel Convention on the Transboundary Movement of Hazardous Wastes and Their Disposal (Basel Convention) where publicprivate partnerships are firmly embedded in the legal and institutional framework of the Convention. The lessons learnt from initiatives under the Basel Convention, notably the Mobile Phone Partnership, will then be discussed. The chapter will conclude by drawing lessons for publicprivate partnerships in relation to technology transfer under the international climate change regime.

\subsection{TECHNOLOGY TRANSFER IN THE UN CLIMATE CHANGE REGIME}

The UNFCCC and the Kyoto Protocol both contain provisions on technology transfer. All 195 parties to the Convention are required to promote and cooperate with respect to climate change mitigation technologies. ${ }^{17}$ In practice, details and the institutional framework for such cooperation have evolved gradually during the two decades following the adoption of the UNFCCC in 1992. This is because the UNFCCC, like many other MEAs, endorses a procedural approach and the regime continues to develop through further international negotiations and new legal instruments such as the Kyoto Protocol. The annual sessions of the Conference of the Parties (COP) constitute the key forum for these continuing negotiations. Importantly for technology transfer, the COP is assisted in its work by two Subsidiary Bodies (SBs), the Subsidiary Body for Implementation (SBI) and the Subsidiary Body for Scientific and Technological Advice (SBSTA), which typically convene twice per year. Technology transfer is on the agenda of both of these bodies, which is 
significant in providing the parties a recurring opportunity to put forward and develop new ideas, and improve existing mechanisms for cooperation.

Technology cooperation under the UNFCCC has slowly intensified since the parties decided, in 1998, to give more attention to technology issues, launching a consultative process on technology at COP 4 in Buenos Aires. ${ }^{18}$ The consultations led to agreement on a new framework for technology in 2001. ${ }^{19}$ This included the establishment of the internet portal 'TTClear' on technology-related information. Another element of the framework was the creation of the Expert Group on Technology Transfer (EGTT), recently replaced by the new Technology Mechanism (see below). The EGTT, constituted of 20 experts, convened twice a year ${ }^{20}$ and was tasked with enhancing technology transfer under the UNFCCC. It provided an annual report on its activities to the SBs, based on which the UNFCCC parties developed further guidance. While the EGTT has ceased to exist, some of its work remains relevant for international technology cooperation. The EGTT developed, for instance, performance indicators to monitor the effectiveness of the framework for technology transfer under the UNFCCC. ${ }^{21}$ It produced recommendations on future financing options for enhancing development, deployment, diffusion and transfer of technologies. ${ }^{22}$ The EGTT also prepared a report on options to facilitate collaborative technology R\&D. ${ }^{23}$

As a part of the technology framework, a number of developing countries have also prepared Technology Needs Assessments (TNAs) under the UNFCCC. ${ }^{24}$ The Global Environment Facility (GEF), which is the operating entity of the Convention's financial mechanism together with the new Green Climate Fund established in 2010, has provided some funding for these activities. When it comes to technologies for climate change mitigation, the most commonly identified needs relate to renewable energy, improved crop management, energy-efficient appliances, waste management, forestry, as well as cleaner and more efficient vehicles. ${ }^{25}$ Concerning adaptation to the adverse impacts of climate change, the most common technology needs in developing countries concern crop management, efficient water use, improving irrigation systems, technologies for afforestation and reforestation, and technologies to protect against and accommodate rises in sea level. ${ }^{26}$

In their TNAs, developing countries have also identified barriers to technology transfer. The main ones are economic and market barriers, in particular, lack of finance. ${ }^{27}$ Parties have also suggested measures to address these barriers. These include measures to increase foreign investment and increase participation of the private sector in technology transfer ${ }^{28}$ Parties also envisage introducing supporting policies and laws, improving collaborative research and development of technologies, and 
increased public awareness. ${ }^{29}$ Most countries pointed out that existing in-country capacity was insufficient to adequately address national technology needs, indicating that there remains a large demand for capacitybuilding support within developing countries. ${ }^{30}$

The contribution of these measures to technology transfer has been negligible. Recognizing this, UNFCCC parties have agreed on the need to strengthen international cooperation on climate technologies. In 2008, COP 14 in Poznan, Poland, adopted the Poznan Strategic Programme on Technology Transfer. In 2010, COP 16 in Cancun, Mexico, resulted in agreement on the new Technology Mechanism (see below). Before turning to the new Technology Mechanism, we will discuss in detail the CDM under the Kyoto Protocol, which constitutes the most prominent public-private partnership involving the transfer of climate technologies.

\subsection{TECHNOLOGY TRANSFER UNDER THE CLEAN DEVELOPMENT MECHANISM}

The CDM is one of the three market-based flexibility mechanisms under the Kyoto Protocol. ${ }^{31}$ Together with the EU Emissions Trading Scheme, the CDM has been driving the rapid growth of the international carbon market during the past decade. It has been estimated that by the end of the Kyoto Protocol's first commitment period in December 2012, the CDM could generate over two billion certified emission reductions (CERs) and rally new funding for clean technologies. ${ }^{32}$ Against this background, the CDM has been described as 'the hottest business on the planet, mobilizing billions of Euros and spawning a whole set of service providers, as well as financial vehicles buying CERs'. ${ }^{33}$ However, after several years of remarkable growth, the primary CDM market began to contract in 2008. This reflects the global economic crisis as well as CDM investors' frustration and overall uncertainty concerning international climate policy in the post-2012 period. $^{34}$

According to Article 12.2 of the Kyoto Protocol, the CDM has two objectives. First, it seeks to assist developed (Annex I UNFCCC, AI) countries in achieving their emission targets and to promote sustainable development in developing (Non-Annex I, NAI) countries. The basic idea underlying the CDM is that a developed country can use CERs from a CDM project in a developing country (where mitigation of greenhouse gas emissions tends to be cheaper) to comply with its legally binding commitment under the Kyoto Protocol to reduce greenhouse gas emissions. The use of offsets from the CDM and the two other Kyoto Mechanisms must, however, be supplementary to domestic emission reductions. 
In practice, the CDM relies on climate-friendly projects that are mostly implemented by the private sector. Indeed, engaging the private sector in the implementation of the Kyoto Protocol can be seen as one of the CDM's most important achievements. ${ }^{35}$ The private sector is engaged in implementation of the CDM both as project owners and as Designated Operational Entities tasked with verifying CDM projects' compliance with the international CDM rules. ${ }^{36}$ However, the private sector's involvement in the CDM was not clear or uncontroversial from the outset. Instead, a market-based approach relying on private actors was initially pitted against an 'interventionist' approach that would have relied on traditional development assistance from the public sector to implement CDM projects. ${ }^{37}$ Those supporting the market-based approach argued that the governments should set the rules for the CDM, while the private sector "which holds the capital and technology necessary to the CDM's success' should be entrusted to design the CDM projects. ${ }^{38}$ Interventionists, in turn, were sceptical of the private sector's ability to assist NAI countries to achieve sustainable development. ${ }^{39}$

To be sure, the CDM has encountered numerous challenges and its contribution to sustainable development remains contested. One of the problems is that projects have been concentrated in emerging economies, while Africa and the least-developed countries (LDCs) have not reaped corresponding benefits from the CDM. China, India, Brazil, Mexico, Malaysia, Indonesia and the Republic of Korea account for the vast majority of CDM projects, leaving other NAI countries with an approximate 17 per cent share. ${ }^{40}$ Only 48 projects have been registered in Africa, against 1,980 registered projects in Asia and the Pacific, and 482 in Latin America and the Caribbean. ${ }^{41}$ It has also been argued that contrary to the initial assumption, most CDM projects actually receive their funding from developing country investors rather than from developed countries. ${ }^{42}$

The CDM's contribution to sustainable development is also subject to debate because more than half of CERs issued by June 2010 resulted from projects involving destruction of the industrial greenhouse gas HFC-23. These CDM projects are located mostly in China where companies manufacturing the refrigerant HCFC-22 are paid to capture and incinerate HFC-23, which is generated during the production process. The main incentive for such projects comes from the fact that HFC-23 is a potent greenhouse gas, meaning that CDM projects involving its destruction can generate cheap carbon credits. The problem, then, is that HFC projects result in some perverse incentives. The production of HCFC-22 is being phased out under the Montreal Protocol on Substances that Deplete the Ozone Layer but revenue from the sale of CERs may 
create an incentive to continue its production. ${ }^{43}$ Many countries in the UNFCCC negotiations have supported withdrawing the eligibility of such projects under the CDM. The governance of the CDM also has received some strong criticism. ${ }^{44}$ From the perspective of the private sector, the rules and institutions governing the CDM have not fulfilled essential procedural guarantees: decisions by the CDM Executive Board have been difficult to predict and lacking in adequate justification, there has been no possibility to appeal the decisions ${ }^{45}$ and doubts have been raised concerning the impartiality of the board members. ${ }^{46}$

While recognizing these challenges, the CDM is widely perceived as a significant innovation and there is widespread support for its continuation beyond 2012. This is because the CDM 'has introduced the concept of market-based mechanisms to the realm of international law and creates a framework for public-private partnerships which support the objectives of the Kyoto Protocol'. ${ }^{47}$ The CDM has also served to increase awareness of climate change. ${ }^{48}$ Relevant for technology transfer, the CDM has been characterized as a platform on which technology providers from developed countries can build their marketing efforts in developing countries, ${ }^{49}$ although the CDM does not have a specific mandate concerning technology transfer. ${ }^{50}$ Still it has contributed to this objective by financing emission reductions from projects using climate technologies that have not been previously available in the country hosting the CDM project. $^{51}$ It has also been noted that the CDM has contributed to financing technologies for climate change adaptation through a 2 per cent levy on CERs. ${ }^{52}$ The share of proceeds goes to the Adaptation Fund which was established under the Kyoto Protocol and focuses on funding concrete adaptation projects and programmes in developing countries.

In practice, the CDM has made a relatively important contribution to technology transfer. In June 2010, at least 30 per cent of the 4,984 projects in the CDM pipeline involved technology transfer. ${ }^{53}$ The rate of technology transfer varies significantly between various CDM project types; for instance, all $\mathrm{N} 2 \mathrm{O}$ projects involved technology transfer in contrast to only 13 per cent of all hydro projects. ${ }^{54}$ Also, methane avoidance projects ( 78 per cent) and landfill-gas projects ( 82 per cent) often involved technology transfer, along with wind (34 per cent), biomass (also 34 per cent) and energy efficiency (39 per cent) projects. ${ }^{55}$ Most of the technologies transferred through the CDM originated from developed countries, with five countries (Germany, United States, Japan, Denmark and China) accounting for more than half of them. ${ }^{56}$ It is interesting to note, however, that technology transfer was more common during the early years of the CDM than it is today. ${ }^{57}$ This is particularly evident in countries hosting the majority of CDM projects, namely, 
China, India and Brazil. ${ }^{58}$ Other countries show a more modest declining trend. ${ }^{59}$ One of the reasons could be that the need for international technology transfer declines as local knowledge and sources become more established and awareness of the available technologies grows. ${ }^{60} \mathrm{In}$ other words, the need for further international inflow of technology is reduced while the need for technology diffusion within the country becomes more prominent. ${ }^{61}$ Questions concerning intellectual property rights (IPRs) have not been extensively discussed or analysed in the context of the CDM. It has, however, been found that perceived and effective protection of IPRs could play a role in attracting CDM projects to a developing country. ${ }^{62}$ There is also some evidence to suggest that technology licences and other agreements concerning the knowledge and/or equipment imported through CDM projects may help to overcome barriers to technology transfer related to IPRs. ${ }^{63}$

All of this goes to show that market-based mechanisms such as the CDM can play an important role in the transfer of climate-friendly technologies, especially during the early years of a host country's involvement. ${ }^{64}$ At the same time, the CDM's contribution is not likely to be sufficient to respond to the climate change challenge and satisfy the ultimate objective of the UNFCCC regime. Hence the recent efforts to strengthen technology cooperation under the UNFCCC.

\subsection{TECHNOLOGY TRANSFER IN THE FUTURE CLIMATE REGIME}

Technology is one of the so-called building blocks of the future international climate regime, identified in the Bali Action Plan adopted by COP 13 in 2007.65 In other words, technology is a key part of the ongoing negotiations to strengthen international climate cooperation. According to the Bali Action Plan, the mandate of the negotiators is to develop 'effective mechanisms and enhanced means for the removal of obstacles to, and provision of financial and other incentives for, scaling up the development and transfer of technology to developing country parties' ${ }^{66}$ They are also tasked to 'accelerate deployment, diffusion and transfer of affordable environmental technologies' and promote 'cooperation on research and development of current, new and innovative technologies'. ${ }^{67}$

The original deadline for completing negotiations under the Bali Action Plan was the historic 2009 UN Climate Change Conference in Copenhagen. Despite unprecedented media attention and participation by nearly 120 world leaders, Copenhagen failed to provide a meaningful 
outcome. After several difficulties during the two-week Conference, negotiations by a small, informal group comprising several world leaders produced a document entitled the Copenhagen Accord. ${ }^{68}$ However, UNFCCC parties were unable to find consensus on the adoption of the Copenhagen Accord as a COP decision. Instead, after a long and acrimonious debate, the COP agreed to 'take note' of the Accord and also extended the deadline for completing the negotiations on the Bali Action Plan by one more year. ${ }^{69}$ Given that the Copenhagen Accord was not formally adopted, its contents could not be made operational under the UNFCCC regime. Had it been adopted, the Copenhagen Accord would have, inter alia, established a new technology mechanism. ${ }^{70}$ The Accord also envisaged the provision of scaled-up funding to developing countries, including through a new Copenhagen Green Fund. ${ }^{71}$ The Accord left, however, a number of key details open, including whether there would have been a specific funding window for technology in the green fund.

Building on work done before and during Copenhagen, the 2010 UN Climate Change Conference in Cancun resulted in the adoption of a package of decisions known as the Cancun Agreements. The key element of the Cancun Agreements is Decision 1/CP.16 which established the new Technology Mechanism. The mechanism comprises the Technology Executive Committee (TEC) and the Climate Technology Center and Network $(\mathrm{CTCN}) .^{72}$ The Technology Mechanism operates under the guidance of and is accountable to the COP. ${ }^{73}$ In addition, the Cancun Agreements established the Green Climate Fund which will also be relevant for technology cooperation under the UNFCCC. The agreement to create the Green Climate Fund was a historic achievement, especially when seen in the context of the mid-term commitment by developed countries to jointly mobilize US $\$ 100$ billion per year by 2020 to address the needs of developing countries. ${ }^{74}$ The detailed design of the Fund remains outstanding but UNFCCC parties have already agreed that it will use thematic funding windows ${ }^{75}$ It therefore looks possible that technology will get its own thematic funding window in the Green Climate Fund.

Details of the new Technology Mechanism were developed through further negotiations by COP 17 in Durban, South Africa, at the end of 2011. The Technology Executive Committee began its work in September 2011 and COP 17 resulted in agreement on its modalities and rules of procedure. In addition, COP 17 adopted the terms of reference of the CTCN and preparations began for selecting its host institution. The Cancun Agreements, which are the focus of this analysis written before COP 17, listed general functions for both bodies. ${ }^{76}$ The TEC is designed to assist the UNFCCC and its parties and it will perform three broad 
functions. ${ }^{77}$ It will give policy guidance, play a facilitative role and undertake synthesis and analysis. ${ }^{78}$ The CTCN will focus primarily on developing countries. ${ }^{79}$ It will play a facilitative and advisory role and provide assistance directly or through regional centres and the Network. ${ }^{80}$ Given that the functions of the two bodies are related and complementary, one of the challenges in the further negotiations is to ensure that the new Technology Mechanism forms an integrated and coherent entity. ${ }^{81}$ To finalize the outstanding details, the Cancun Agreements created a work programme on technology transfer. The work programme will consider additional functions for the TEC and the CTCN, their relationship, as well as the relationship between the Technology Mechanism and the Convention's financial mechanism (which will be operated by the Green Climate Fund). ${ }^{82}$

Interestingly for our present focus, the new Technology Mechanism is also tasked with promoting public-private partnerships. Functions of the TEC include promoting and facilitating collaboration on mitigation and adaptation technologies between governments, the private sector, nonprofit organizations and academic and research communities. ${ }^{83}$ It will also seek cooperation with relevant international technology initiatives, stakeholders and organizations, and promote coherence and cooperation across technology activities, including activities under and outside the Convention. ${ }^{84}$ Similarly, the functions of the CTCN, as listed in the Cancun Agreements, include 'stimulating and encouraging, through collaboration with the private sector, public institutions, academia and research institutions, the development and transfer of existing and emerging environmentally sound technologies, as well as opportunities for North-South, South-South and triangular technology cooperation' ${ }^{85}$ The CTCN will also facilitate international partnerships among public and private stakeholders to accelerate the innovation and diffusion of environmentally sound technologies to developing country parties. ${ }^{86}$

It has been argued that the new Technology Mechanism represents a potential step towards a more dynamic approach to technology issues under the UNFCCC that is geared towards fostering public-private partnerships; promoting innovation; catalyzing the use of technology road-maps or action plans; mobilizing national, regional and international technology centres; and facilitating joint R\&D activities. ${ }^{87}$ At the same time many challenges lie ahead, including the need to endow the new Technology Mechanism with sufficient resources. ${ }^{88}$ Institutional issues must also be clarified, including the relationship between the TEC and the CTCN, as well as the relationship between the new Green Climate Fund and the Technology Mechanism. ${ }^{89}$ The question of IPRs also 
remains controversial in the UNFCCC negotiations and ultimately all references to IPRs were dropped from the Cancun Agreements. ${ }^{90}$

The sections below will focus on lessons learned from public-private partnerships in general and from the specific example of the Mobile Phone Partnership under the Basel Convention that was created to address the problem of e-waste ${ }^{91}$ in developing countries. Based on these, the concluding section includes some ideas on how these experiences could benefit public-private partnerships under the UNFCCC and its new Technology Mechanism.

\subsection{PUBLIC-PRIVATE PARTNERSHIPS: EXPERIENCES UNDER OTHER MEAS}

Leaving aside the CDM, public-private partnerships would be a relatively new element in the governance set-up of the international climate change regime. ${ }^{92}$ These instruments have, however, already been experimented with within the UN system and in other MEAs for quite some time. It seems therefore useful to take stock of experience gained elsewhere and discuss whether the lessons learnt could be relevant for devising tools for increased involvement of the private sector in the transfer of climate technologies under the international climate change regime.

Starting in the mid-1990s, the United Nations, its agencies and programmes have increasingly embarked on the establishment and management of partnerships with the private sector, leading to a proliferation of initiatives that have now overtaken by some distance our understanding of their nature and impact. ${ }^{93}$ Under the leadership of former UN Secretary-General Kofi Annan, the development of UN-business partnerships turned into 'an imperative for the UN' 94 to support the social and environmental pillars of sustainable development. This vision was epitomized by the launch of the Global Compact ${ }^{95}$ and endorsed intergovernmentally in the 2000 Millennium Declaration as a fundamental component of the pursuit of development and poverty eradication. ${ }^{96}$ Since the 2002 World Summit on Sustainable Development in Johannesburg, ${ }^{97}$ public-private partnerships have proliferated within the framework of UN bodies and programmes as well as Secretariats of MEAs. ${ }^{98}$

The definition of partnerships remains an open question. ${ }^{99}$ The 2009 Guidelines on Cooperation between the UN and the Business Sector described them (without asserting that this is the only definition) as a "voluntary and collaborative agreement between one or more partners of the UN system and non-State actors in which all participants agree to work together to achieve a common purpose of undertaking specific tasks 
and to share risks, responsibilities, resources, competencies and benefits'. ${ }^{100}$ The Guidelines also caution that:

Nothing in such a partnership shall be deemed to establish either party as the agent of the other party or create a 'legal' partnership or joint venture between the parties. Neither party has power to bind the other party or to contract in the name of the other party or create a liability against the other in any manner whatsoever. ${ }^{101}$

Notwithstanding the haphazard fashion in which partnerships have been set up in the UN system, the 2009 Guidelines identify three categories of cooperation between the UN and the business sector, two of which are particularly relevant for present purposes. First, 'core business operations and value chains' involve mobilizing the innovative technologies, processes, financing mechanisms, products, services and skills of the business sector. Secondly, 'advocacy and policy dialogue' relate to initiatives that promote and advance a specific cause in support of the UN goals or promote multi-stakeholder dialogue on issues related to the purposes and activities of the UN with a view to promoting a concept of corporate responsibility. The latter therefore aims at working with companies to bring about change in their internal business practices to align with UN goals, and developing norms or guidelines to engage stakeholders in support of UN goals. ${ }^{102}$

Accordingly, public-private partnerships have served concrete goals. In the specific context of environmental protection, public-private partnerships have spurred cooperation between MEA Secretariats and parties and the private sector in the collaborative development of standards directly applying to the private sector. They are also used as a way for the private sector to participate in funding MEAs and in MEA communication and outreach activities. In addition, through those initiatives private companies may be called to contribute to the implementation of MEA standards and even to accept standards of behaviour that go beyond the obligations contained in a given agreement. The latter option is particularly helpful when state parties to a convention are unable to reach agreement on tighter measures of protection or on emerging issues and the legal definitions and scope of an MEA do not allow for a broader interpretation of these new issues. ${ }^{103}$

While these voluntary initiatives may be useful tools to effectively involve the private sector in the implementation of agreed environmental goals, their potential is, however, often not realized. Common problems among public-private partnerships in the environmental sector include lack of uniform practice, difficulty in moving from the development of a 
partnership to its implementation stage, and lack of systematic monitoring or assessment of these initiatives. These shortcomings may be due to the underlying difficulty in agreeing with private companies on a set of time-bound targets and binding objectives. This jeopardizes both the achievement of practical results and the possible monitoring of impacts. ${ }^{104}$ Possible risks in partnering with the private sector need to be fully explored in designing new partnership initiatives. These risks include partnering with companies that may be economically and politically more powerful than certain states parties or have a vested interest in the use of certain environmental resources, thus potentially threatening the integrity of the MEA process. Risks also encompass alienating partner NGOs, indigenous peoples and other stakeholders and undermining the independence of the MEA because of funding provided by the private sector. ${ }^{105}$

To address these issues, it should be emphasized that the voluntary nature of partnerships, i.e., the fact the business entities decide voluntarily whether to enter into one or not, does not necessarily mean that they should function without some basic agreed-upon rules. ${ }^{106}$ As in contract law, the fact that the private companies enter voluntarily into a partnership does not necessarily imply that the company will not assume a certain obligation once the partnership has come into existence. The possibility of overcoming the false dichotomy 'voluntary vs non-binding' in the corporate accountability debate ${ }^{107}$ may well reside in the development of more precise agreements or action plans as a clear basis of minimum binding rules for the implementation of MEA-business partnerships. In this way, partnerships would become more structured, more easily monitored and assessed in their impacts.

Therefore, a fair, transparent and effective MEA-private sector partnership needs to build a clear framework composed of time-defined targets, minimum standards of conduct and transparency guarantees for joining the partnerships and for decision-making in its framework. The adoption of guidelines on conflict of interest may also be needed. ${ }^{108}$

\subsection{A CASE IN POINT: THE MOBILE PHONE PARTNERSHIP UNDER THE BASEL CONVENTION}

The experience of the Mobile Phone Partnership under the Basel Convention $^{109}$ is quite illustrative of gradually developing a framework within an MEA for public-private partnerships. Although it does not concern technology transfer as such, it is analysed here with a view to highlighting how embedding public-private partnerships in the legal and 
institutional structure of an MEA may serve to ensure that such voluntary instruments 'live up to, rather than evade, responsibility and commitment'. ${ }^{110}$ In particular, the Basel Convention experience shows how public-private partnerships can be useful ways to make progress when intergovernmental negotiations are addressing a very complex legal issue, namely, whether old and used mobile phones exported for repair to developing countries come within the scope of the Basel Convention. ${ }^{111}$ In these situations, states, being unable to reach consensus, allow partnerships to identify and discuss options to address technical and related legal issues in a more informal environment without renouncing the right to have the final say on legal questions. ${ }^{112}$

The Mobile Phone Partnership initiative was established through a decision of the COP of the Basel Convention in 2002 following a declaration by mobile phone manufacturers committing to enter into a partnership with the Basel Convention and other stakeholders. ${ }^{113} \mathrm{~A}$ Working Group was established with participation by parties, manufacturers and NGOs, and gradually by other private sector representatives (mobile phone recyclers and refurbishers, and telecom operators and their associations). The Working Group produced a series of technical guidelines and also discussed legal matters, namely, how and when the Basel Convention applies to the transboundary movement of used mobile phones destined for reuse after repair, refurbishment or upgrading in the importing country. ${ }^{114}$

The framework for the partnership was initially formalized in a set of terms of reference (TORs) which defined the roles of different partners, responsibilities, objectives and ground rules. It was agreed that TORs could be modified. The TORs also provided for a facilitated process with a co-management team of stakeholders selected from the partnership to avoid or resolve conflicts, as well as clearly articulated and collectively developed conflict management ground rules. Then, a work plan was developed with clear milestones, indication of necessary budgetary resources and the possibility of undertaking pilot projects. All these were presented to the COP for regular updates and provision of inputs; there were also continued opportunities for providing inputs on documents elaborated by the partnership and made available to the public. ${ }^{115}$

The Working Group presented a series of options to the COP through a chairman's paper. ${ }^{116}$ In 2009, COP 9 of the Basel Convention adopted as a voluntary document and 'without prejudice to national legislation' most of the sections of the Guidance Document on the Environmentally Sound Management of Used and End of Life Telephones, ${ }^{117}$ following its review by the COP's subsidiary body, the Open-Ended Working Group (OEWG), and as amended by the Secretariat. COP 9 also requested parties and other 
interested stakeholders to submit comments on one outstanding section of the guidance document, as amended, to the Secretariat (on contentious options for the transboundary movement of used and end-of-life mobile phones) while inviting them to use and continue to test the guidance document. The COP further decided that the Mobile Phone Working Group had successfully completed its mandate and that any follow-up tasks that might be required would be carried out by an ad hoc follow-up group. ${ }^{118}$ The Partnership has now moved to a second stage in which participating private entities will test the technical guidelines in a facility type environment to see whether changes are required to recommendations. ${ }^{119}$

The COP further expanded work based on public-private partnerships by adopting a work plan for e-waste, including work on the Partnership for Action on Computing Equipment; ${ }^{120}$ encouraging parties and signatories to provide voluntary contributions and engage in partnerships; inviting the continued development of pilot projects by parties and stakeholders; establishing a working group operating under the OEWG as the operating mechanism for the Partnership for Action on Computing Equipment; ${ }^{121}$ and adopting the Convention Partnership Programme work plan for 2009-2010 as a key instrument for supporting the implementation of the Strategic Plan for the Implementation of the Basel Convention in conjunction with all relevant and interested partners. ${ }^{122}$

Xaver Perrez has aptly underlined that the Basel Convention Mobile Phone Partnership not only resulted in the production of technical guidelines but also contributed to the development of specific activities and policies supporting the implementation of the Convention in a contentious area, as well as raising the political profile of the question at the international and national level. ${ }^{123}$ The inclusion of public-private partnerships in the fabric of an MEA governance structure has thus been considered essential to ensure that partnership implementation is not ad hoc but rather part of a broader and comprehensive policy of global coverage. It served to avoid duplication, and ensure that all countries can benefit from the initiative. It also guaranteed the political, financial and institutional sustainability of the initiative. It further provided an adequate institutional structure for review, assessment and development of the voluntary initiative. ${ }^{124}$

\subsection{LESSONS LEARNT FROM PUBLIC-PRIVATE PARTNERSHIPS}

Partnerships can thus be a useful approach to building solutions for increased access to and transfer of climate technologies as long as their 
risks and shortcomings are actively managed. They can serve as a pragmatic tool to contribute to ongoing interstate negotiations and move beyond deadlocks, for instance, on the question of IPRs and access to climate technologies. Partnerships are a voluntary tool that can be formalized through an agreement with the MEA Secretariat and/or TORs and work plans to be endorsed by the COP so as to be embedded in the governance structure of MEAs as a multi-stakeholder endeavour. MEA Secretariats can play the role of facilitator and neutral broker. MEA parties through the COP, subsidiary bodies and as active participants in the partnership meetings and activities will be able to oversee the process. NGOs would also be able to provide inputs on an equal footing with business representatives.

Benefits arising from public-private partnerships under MEAs include concrete contributions to the attainment of the objectives of MEAs; supplementing government initiatives with complementary initiatives on the ground; elaboration of standards as a contribution to ongoing negotiations or temporary alternatives until parties find agreement; and pilot projects to field test agreed standards in different regions. ${ }^{125}$

Before concluding a partnership, however, all risks should be assessed and managed. The MEA Secretariat and relevant stakeholders will have to reach agreement on specific targets. Terms of representation of different groups of stakeholders will have to be worked out, with special provision for ensuring participation of representatives from developing countries. Agreement will have to be reached also on incentives for engagement, ${ }^{126}$ responsibilities, communication, use of the MEA logo, dissemination of information and drafts, monitoring, evaluation and review processes. Such agreements are ideally to be formalized in an exchange of letters/declarations, a memorandum of understanding or an agreement $^{127}$ subject to review and endorsement by the COP. The selection of specific partners is also a delicate operation for which the UN guidelines call for a due diligence process and collaboration or linkages with the Global Compact. ${ }^{128}$ Other details of the partnership will also be developed in a participatory and transparent manner ${ }^{129}$ through terms of reference and work plans, once again subject to the review and endorsement of the COP and possibly relevant subsidiary bodies. These subsequent arrangements will need to address: needed resources at the MEA Secretariat level and for the functioning of the partnerships; guarantees for the application of the partner selection scheme and transparency in such selection; monitoring; and mechanisms for avoiding conflict of interest and conflict management. 


\subsection{CONCLUSIONS: HOW TO FACILITATE ACCESS TO CLIMATE TECHNOLOGIES WITH PUBLIC-PRIVATE PARTNERSHIPS?}

With specific reference to technology transfer it has been observed, including by Santamauro and by Davies in this collection, that publicprivate partnerships have already been experimented with for the purpose of developing and disseminating new technologies by creatively tackling IPR issues, and have the potential to facilitate the matching of technologies with local needs while addressing IPR issues and creating incentives for innovation. ${ }^{130}$ Accordingly, the Basel partnership may provide some innovative ideas for the establishment of climate innovation partnerships that are embedded in the legal and institutional framework of the international climate change regime.

It should be stressed, however, that climate-specific challenges are unique in their complexity: the e-waste problem is much more specific and confined in the range of economic sectors concerned. Climate change-related questions of ensuring that developing countries 'leap-frog' and directly use green technologies in all economic sectors imply that the relevant private partners are much more difficult to identify and mobilize. Furthermore, in the climate change context, technologies will also be needed for adaptation, which also broadens the scope of the partnership and the range of possible partners. Nonetheless, the Basel example may still be useful in thinking about the purposes that public-private partnerships may serve under the new Technology Mechanism, such as (1) to identify ways to deal with IPR issues in specific project-based instances (for instance, by developing standard contract clauses); (2) to develop standards for generally dealing with IPR issues in the context of the transfer of climate technology for consideration by the COP; and (3) to pilot the transfer of climate technology based on standard clauses/ guidelines related to IPR issues.

More specifically the TEC could arrange for public-private partnerships aiming to contribute to the development of policy and technical guidelines as well as standard contract clauses, including on IPR issues, to facilitate technology diffusion in key sectors in the context of its mandate to make recommendations to the COP and ensure coherence among technology transfer and dissemination activities. The TEC would thus be responsible for the selection of appropriate partners, on the basis of a due diligence process and possible links with the Global Compact. It could also oversee the collaborative development of the TORs and rules for the management of possible conflicts and conflicts of interest which 
would then be subject to endorsement by the COP. In addition, the TEC would be responsible for ensuring transparency and equal participation in the partnership and periodic review of its work plan and relevant outputs. On the other hand, the CTNC, which is basically to 'provide services to developing countries', ${ }^{131}$ could facilitate the forging of public-private partnerships at the local level. It could also serve for more practical purposes, such as to launch pilot projects on the basis of the guidelines developed under the TEC as part of its task to facilitate networks of national, regional or sectoral initiatives. The CTNC would thus primarily concentrate on selecting, following due diligence, and monitoring local partners. In addition, these local partnerships could contribute to its tasks related to providing information on available technologies. Also in this case, reporting back to the COP and ensuring compliance with the general and more specific guidance adopted by the TEC would be an essential element to ensure that the risks of public-private partnerships are actively managed with a view to avoiding or minimizing them while effectively contributing to achieving the objectives of the international climate change regime.

Finally, one should not forget that the new Technology Mechanism will likely be a complement to technology transfer under the CDM and possible new market mechanisms. The carbon market is estimated to play an important role in providing the scale of funding needed to address the climate challenge but other public-private partnerships will also be needed along with other tools, such as funding mechanisms, capacity building and international R\&D cooperation. ${ }^{132}$

\section{NOTES}

* The authors wish to thank Ines Sofia de Correia, David Rossati and Kasey McCall-Smith for their excellent research assistance.

1. N. Stern, The Economics of Climate Change: The Stern Review (Cambridge University Press, Cambridge, 2006) 393-4.

2. International Energy Agency, World Energy Outlook 2009 (OECD/IEA, Paris, 2009).

3. IPCC, 'Summary for policymakers', para. 19 in B. Metz et al., Climate Change 2007: Mitigation of Climate Change. Working Group III Contribution to the Fourth Assessment Report of the Intergovernmental Panel on Climate Change (Cambridge University Press, Cambridge, 2007) 3-23.

4. Ibid. Also note the discussion on the difference between technology 'transfer' and 'diffusion' in A.A. Latif, The Climate Technology Mechanism: Issues and Challenges, ICTSD Information Note No. 18 (March 2011), who emphasizes that the latter term implies the involvement of the private sector, while the former relates to relationships between public institutions.

5. UNFCCC Secretariat, Fact Sheet: A Technology Revolution to Address Climate Change, available at http://unfccc.int/press/fact_sheets/items/4989.php. 
6. IEA, n. 2 above.

7. Ibid. The IEA estimates that in the reference scenario where reliance on fossil fuels continues, the required investment will amount cumulatively to US $\$ 26$ trillion by 2030 and some US\$10.5 trillion more will be needed to limit global average temperature increase to 2 degrees Celsius from pre-industrial times. According to the IEA, the additional cost would be partly offset by health and energy-security benefits.

8. Stern, n. 1 above, at 349 et seq.

9. Ibid. 416.

10. Ibid. 412-15.

11. T. Forsyth, 'Enhancing climate transfer through greater public-private cooperation: lessons from Thailand and the Philippines' (2005) 29(2) Natural Resource Forum 165, reproduced at LSE Research Online, available at http://eprints.lse.ac.uk/4735/.

12. Ibid. 3 .

13. Ibid.

14. Ibid.

15. United Nations Framework Convention on Climate Change (UNFCCC) 1771 UNTS 107 (2008). COP Decision 1/CP.13, UN Doc. FCCC/CP/2007/6/Add.1, Bali, Indonesia, 3-15 December 2007. The other building blocks are mitigation, adaptation and finance. Technology has often been linked with capacity building in the negotiations.

16. COP Decision 1/CP.16, UN Doc. FCCC/CP/2010/7/Add.1, Cancun, Mexico, 29 November-10 December 2010, para. 123.

17. UNFCCC, Art. 4.1. UNFCCC, Arts 4.3 and 4.5 provide that developed country parties should provide new and additional financial resources to support the transfer of technology and take all practicable steps to promote, facilitate and finance the transfer of, or access to, environmentally sound technologies and knowhow to developing country parties. Article 11.1 indicates that financial resources shall be provided for the transfer of technology on a grant or concessional basis. Article 10(c) of the Kyoto Protocol 1997 to UNFCCC 23030 UNTS 148 reiterates the requirement on all parties to cooperate in the development, application, diffusion and transfer of environmentally sound technologies that are in the public domain. Article 11.2 of the Kyoto Protocol repeats the commitment of developed country parties to provide financial resources for technology transfer.

18. UNFCCC Secretariat, United Nations Framework Convention on Climate Change: Handbook (UNFCCC, Bonn, 2006) 139.

19. Ibid. The five central elements of the framework were technology needs and needs assessments, technology information, enabling environments, capacity building and mechanisms for technology transfer. The framework is based on Decision 4/CP.7.

20. Ibid. 143 .

21. UNFCCC Secretariat, UN Doc. FCCC/SBI/2009/4 (31 May 2009).

22. UNFCCC Secretariat, UN Doc. FCCC/SBI/2009/2 (30 April 2009).

23. UNFCCC Secretariat, UN Doc. FCCC/SBSTA/2010/INF.11 (24 November 2010).

24. The reports are available at http://unfccc.int/ttclear/jsp/TNAReports.jsp.

25. UNFCCC Secretariat Factsheet, n. 5 above.

26. Ibid.

27. Ibid.

28. Ibid.

29. Ibid.

30. Ibid.

31. The CDM is based on Art. 12 of the Kyoto Protocol. Detailed rules on its implementation are contained in UNFCCC, Decision 3/CMP.1, Modalities and 
procedures for a clean development mechanism as defined in Article 12 of the Kyoto Protocol, UN Doc. FCCC/CMP/2005/8/Add.1 (30 March 2006).

32. UNFCCC Secretariat, 'CDM in numbers', available at http://cdm.unfccc.int/ Statistics/index.html.

33. S.E. Lütken and A. Michaelowa, Corporate Strategies and the Clean Development Mechanism: Developing Country Financing for Developed Country Commitments? (Edward Elgar Publishing, Cheltenham/Northampton, MA, 2008) 26-7.

34. K. Capoor and P. Ambrosi, The State and Trends of the Carbon Market (World Bank, Washington, DC, 2009) 32.

35. For an overview of the various roles that private actors play in implementation of the CDM, see K. Kulovesi, 'The private sector and implementation of the Kyoto Protocol: experiences, challenges and prospects' (2007) 17(2) RECIEL 145.

36. Ibid. $150-52$.

37. J. Werksman, 'The Clean Development Mechanism: unwrapping the Kyoto surprise' (1998) 7(2) RECIEL 147 at 153.

38. Ibid.

39. Ibid.

40. UNFCCC Secretariat, 'CDM statistics: registered project activities by host party', available at http://cdm.unfccc.int/Statistics/Registration/NumOfRegisteredProjBy HostPartiesPieChart.html.

41. UNFCCC Secretariat, 'CDM statistics: registered project by region', available at http://cdm.unfccc.int/Statistics/Registration/RegisteredProjByRegionPieChart.html.

42. Lütken and Michaelowa, n. 33 above, at 148.

43. CDM-Meth panel, Note on AM0001 'Incineration of HFC 23 Waste Streams', 44th meeting report, Annex 2, available at https://cdm.unfccc.int/Panels/meth/meeting/10/ 044/mp44_an02.pdf.

44. C. Streck and J. Lin, 'Making markets work: a review of CDM performance and the need for reform' (2008) 19(2) European Journal of International Law 409.

45. In December 2009, COP/MOP 5 requested that the CDM Executive Board develop an appeals procedure: UNFCCC Secretariat, Decision 2/CMP.5, Further guidance relating to the Clean Development Mechanism, UN Doc. FCCC/KP/CMP/2009/21/ Add.1 (30 March 2010).

46. It was not until 2009 that the CDM Executive Board adopted a Code of Conduct for its members. See UNFCCC, Report of Executive Board, B 47, Annex 62 (26-28 May 2009), available at https://cdm.unfccc.int/EB/047/eb47rep.pdf.

47. Streck and Lin, n. 44 above, at 440.

48. Lütken and Michaelowa, n. 33 above, at 165 .

49. Ibid.

50. Furthermore, there is no definition of 'technology transfer' under the CDM and each project participant may therefore use its own interpretation. However, according to the UNFCCC Secretariat's report, 'project participants overwhelmingly interpret technology transfer as meaning the use of equipment or knowledge not previously available in the host country for the CDM project'. S. Seres and H. Haites, Analysis of Technology Transfer in CDM Projects Prepared for the UNFCCC Secretariat (December 2008), available at http://cdm.unfccc.int/Reference/Reports/TTreport/ TTrep08.pdf.

51. J. de Sépibus, Reforming the Clean Development Mechanism to Accelerate Technology Transfer, Swiss National Centre of Competence in Research Working Paper 2009/42 (2009), available at www.nccr-trade.org/fileadmin/user_upload/nccrtrade.ch/wp5/WP\%202009_42_de\%20Sepibus_Reforming\%20the\%20CDM\%20to $\% 20$ acc\%20TT.pdf.

52. Ibid. 
53. UNFCCC, The Contribution of the Clean Development Mechanism under the Kyoto Protocol to Technology Transfer (2010), available at http://cdm.unfccc.int/ Reference/Reports/TTreport/TTrep10.pdf.

54. Ibid. 10.

55. Ibid.

56. Ibid. 11.

57. Ibid.

58. Ibid.

59. Ibid.

60. Ibid.

61. Ibid.

62. Ibid. 24. The report indicates that other factors are also important, such as the criteria that a country applies to the approval of CDM projects. Also relevant are tariffs and other barriers to imports of relevant technologies, as well as restrictions on foreign investment.

63. Ibid. 11 and 22 .

64. Ibid. 11.

65. UNFCCC Secretariat, Decision 1/CP.13, Bali Action Plan, UN Doc. FCCC/CP/ 2007/6/Add.1 (14 March 2008).

66. Ibid.

67. Ibid.

68. UNFCCC Secretariat, Decision 2/CP.15, Copenhagen Accord, UN Doc. FCCC/CP/ 2009/11/Add.1 (30 March 2010). Text of the Copenhagen Accord is included in the decision which 'takes note' of it.

69. UNFCCC Secretariat, Decision 1/CP.15, Outcome of the work of the Ad Hoc Working Group on Long-term Cooperative Action under the Convention, UN Doc. FCCC/CP/2009/11/Add.1 (30 March 2010).

70. Copenhagen Accord, n. 68 above.

71. Ibid.

72. UNFCCC Secretariat, Decision 1/CP.16, Outcome of the work of the Ad Hoc Working Group on Long-term Cooperative Action under the Convention, UN Doc. FCCC/CP/2010/7/Add.1 (15 March 2011).

73. Ibid.

74. Ibid. para. 98.

75. Ibid. para. 102 .

76. See also J. Morgan, Reflections on the Cancun Agreements (World Resources Institute, Washington, DC, 2001), available at http://pdf.wri.org/reflections_on_ cancun_agreements.pdf.

77. B. Wilson (immediate past chair of the EGTT), 'Lessons learned from the preliminary work of the Expert Group on Technology Transfer on the Technology Mechanism', presentation at UNFCCC Expert Workshop on the Technology Mechanism (2011), available at http://unfccc.int/files/meetings/ad_hoc_working_groups/ lca/application/pdf/lessons_learned_from_the_preliminary_work_of_the_egtt_on_ the_technology_mechanism.pdf.

78. Ibid.

79. Ibid.

80. Ibid.

81. Ibid.

82. Decision 1/CP.16, n. 72 above.

83. Ibid.

84. Ibid.

85. Ibid.

86. Ibid 
87. A.A. Latif, 'The new technology mechanism: an opportunity to seize', Real Climate Economics Blog (2010), available at http://triplecrisis.com/spotlight-cancunthe-newclimate-technology-mechanism/.

88. Ibid.

89. Ibid.

90. Ibid.

91. E-waste includes all types of electrical and electronic equipment that has entered or could enter the waste stream, such as end-of-life TVs, computers, mobile phones, etc. In addition to various hazardous materials, e-waste also contains many valuable and precious materials. See generally UNEP, Recycling: From E-Waste to Resources (2009), available at www.unep.org/PDF/PressReleases/E-Waste_publication_ screen_FINALVERSION-sml.pdf.

92. On limited and informal interactions with the private sector in the UNFCCC context, see WBCSD, Ecofys and Climate Focus, Private Sector and the UNFCCC: Options for Institutional Engagement, Final Report (2010), available at www.wbcsd.org/web/energyclimate/WBCSD\%20Ecofys\%20ClimateFocus\%20Final $\% 20$ Report.pdf.

93. J.M. Witte and W. Reinicke, Business UNusual (UN Global Compact Office, New York, 2005) 3.

94. UN Press Release, 'Secretary-General proposes Global Compact on Human Rights, Labour, Environment, in address to World Economic Forum in Davos', UN Doc. SG/SM/6881 (1 February 1999).

95. The Global Compact is a global platform for UN-business partnerships based on ten 'universally accepted' principles in the areas of human rights, environment and anti-corruption, available at www.unglobalcompact.org. For a discussion, see E. Morgera, Corporate Accountability in International Environmental Law (Oxford University Press, Oxford, 2009) ch. 5.

96. UN General Assembly, United Nations Millennium Declaration, UNGA Res. 55/2 (8 September 2000) para. 20.

97. C. Streck, 'The World Summit on Sustainable Development: partnerships as new tools in environmental governance' (2003) 13 Yearbook of International Environmental Law 63.

98. Morgera, n. 95 above, ch. 12.

99. H. Creech and T. Willard, Virtual Exhibition e-Discussions: Working Together for Sustainable Development (Winnipeg, International Institute for Sustainable Development, 2002), available at www.iisd.org/publications/pub.aspx?id=542. For instance, they were defined as "collaborative initiatives focused on finding solutions to sustainable development challenges ... and working to develop comprehensive knowledge management systems to contribute to an environment of informed decision-making' by ECOSOC, Report of the Secretary-General: Partnerships for Sustainable Development, Background Paper no. 1 for the Twelfth Session of the Commission on Sustainable Development, UN Doc. E/CN.17/2004/16 (10 February 2004).

100. UN Guidelines on Cooperation Between the United Nations and the Business Sector (2009) para. 6, available at http://business.un.org/en/assets/83f0a197-b3b8-41ba8843-d8c5b5d59fe1.pdf. See earlier discussion in J. Nelson, Building Partnerships: Co-Operation Between the United Nations System and the Private Sector (UN Global Compact Office, New York, 2002).

101. UN Guidelines n. 100 above, para. 6.

102. Ibid. para. 18.

103. Morgera, n. 95 above, at 251-4.

104. Ibid. ch. 12 
105. CBD Executive Secretary, Private Sector Engagement in the Implementation of the Convention, UN Doc. UNEP/CBD/WG-RI/1/8 (26 July 2005) para. 10.

106. Streck, n. 97 above, at 82.

107. F. Cafaggi, 'Introductory paper' in The Pluridisciplinary Dimension of CSR: Theoretical Questions of Regulation, EUI, Florence, Italy, 11-12 November 2005, available at www.eui.eu/Documents/DepartmentsCentres/Law/Professors/Cafaggi/ 11Nov05.pdf.

108. See e.g., UNEP, Montreal Protocol, Decision XVIII/19: Guidelines for disclosure of interest for groups such as the Technology and Economic Assessment Panel and its technical options committees, UN Doc. UNEP/OzL.Pro.18/10 (16 November 2006).

109. Basel Convention, Guidance document on environmentally sound management of used and end-of-life mobile phones, UN Doc. UNEP/CHW.8/2/ADD.3* (6 October 2006) Annex.

110. F. Xaver Perrez, 'Public-private partnerships: a tool to evade or live up to commitment?' (Geneva, Switzerland, 20-21 March 2009) in Practical Legal Problems of International Organizations: A Global Administrative Law Perspective on Public-private Partnerships, Accountability and Human Rights (Institute for International Law and Justice, New York, 2009). Xaver Perrez specifically refers to the Basel Convention on Mobile Phone Partnerships as a successful experiment in that respect.

111. Ibid. 8 .

112. Note that the informative leaflet published under the Basel Convention on the Mobile Phone Partnership emphasizes the importance in the partnership of establishing a "mechanism for sending legal interpretive questions to the Parties for resolution, such as issues raised during the discussion of the transboundary movement of used and end-of-life mobile phones'. Basel Convention/UNEP, Information Note: Mobile Phone Partnership Initiative (undated) 2, available at www.basel.int/pub/leaflets/leafMPPI.pdf.

113. Basel Convention, Strategic Plan for the Implementation of the Convention (2002), available at www.basel.int/meetings/cop/cop6/StPlan.htm; and Basel Convention, Decision VI/32, UN Doc. UNEP/CHW.6/40 (10 February 2003). Note that publicprivate partnerships had already been addressed in the context of the Basel Convention: see Basel Declaration on Environmentally Sound Management (1999), available at www.basel.int/meetings/cop/cop5/ministerfinal.pdf; and Basel Convention, Decision V/13, UN Doc. UNEP/CHW.5/29 (10 December 1999) 42.

114. Basel Convention, Decision VI/31, UN Doc. UNEP/CHW.6/40 (10 February 2003).

115. J. Myslicki, Lessons Learned from the MPPI and Benefits of Future Private-Public Partnerships in the Framework of the Basel Convention (Federal Environment Agency, Germany, 2010), available at http://ewasteguide.info/Myslicki_2010_ UBA3921, pp. 28-31. See Decisions VII/4; VIII/6.

116. Ibid. 27.

117. Basel Convention, Provisionally Adopted Guidance Document on Environmentally Sound Management of Used and End-Of-Life Mobile Phones, UN Doc. UNEP/ CHW.9/11 (9 June 2008).

118. Basel Convention, COP Decision IX/8: Mobile Phone Partnership Initiative, UN Doc. UNEP/CHW.9/39 (27 June 2008).

119. Myslicki, n. 115 above, at 14.

120. Basel Convention, COP Decision IX/9: Partnership for Action on Computing Equipment (based on Decisions VI/32, VII/3, VIII/2 and VIII/5), UN Doc. UNEP/ CHW.9/39 (27 June 2008).

121. Ibid.

122. Basel Convention, COP Decision IX/7: Convention Partnership Programme Workplan for 2009-2011, UN Doc. UNEP/CHW.9/39 (27 June 2008). 
Public-private partnerships for equitable access to climate technologies 151

123. Xaver Perrez, n. 110 above, at 9 .

124. Ibid. 10 .

125. Myslicki, n. 115 above, at 26.

126. WBCSD, Ecofys and Climate Focus, n. 92 above, at 68.

127. IUCN, A Survey of Guidelines for Not-For-Profit/Private Sector Interaction: Results and Recommendations for IUCN's Forthcoming Operational Guidelines for Private Sector Engagement (IUCN, Geneva, 2005).

128. UN Guidelines, n. 100 above, para. 11. Note that while the UN Guidelines apply only to the UN Secretariat, they are intended to serve as a 'common framework' also for other UN entities (presumably, also the UNFCCC bodies) as a basis for their collaboration with the business sector. UN entities, however, are encouraged to develop more specific guidelines in accordance with their particular mandates and activities (UN Guidelines, n. 100 above, para. 8).

129. Ibid. para. 12(f) on the importance of transparency.

130. K. Maskus and R. Okediji, Intellectual Property Rights and International Technology Transfer to Address Climate Change: Risks, Opportunities and Policy Options, International Centre for Trade and Sustainable Development Issue Paper 32 (2010) 24.

131. Latif, ICTSD Information Note No. 18, n. 4 above, at 9.

132. UNFCCC, The Contribution of the CDM Under the Kyoto Protocol to Technology Transfer (2010), available at http://cdm.unfccc.int/Reference/Reports/TTreport/ TTrep10.pdf. 